\title{
Distributed versus Lumped Optimization of Cropping Pattern and Water Resources Utilization
}

\author{
Case Study: Mobarakabad District, Pasargad Plain, I. R. IRAN
}

\author{
Mohammad Mehdi Ghasemi1 ${ }^{*}$, Mohammad Karamouz ${ }^{2,3}$, Lee Teang Shui1 \\ ${ }^{1}$ Department of Biological and Agricultural Engineering, University Putra Malaysia, Serdang, Selangor, Malaysia \\ ${ }^{2}$ Polytechnic Institute of NYU, New York, USA \\ ${ }^{3}$ University of Tehran, Tehran, Iran \\ Email: ${ }^{*}$ mmghasemi@hotmail.com
}

Received 29 December 2013; revised 6 February 2014; accepted 3 March 2014

Copyright (C) 2014 by authors and Scientific Research Publishing Inc.

This work is licensed under the Creative Commons Attribution International License (CC BY).

http://creativecommons.org/licenses/by/4.0/

(c) (i) Open Access

\begin{abstract}
Several whole-farm agro-economic optimization models have been developed to deal with lumped planning issues in the agriculture sector. However, these models cannot be used to devise appropriate management strategies at land parcel level, because of the differences between farm characteristics, and the increased complexity of the hydrological processes. Based on Spatial Farm Database (SFD) which is consisted of a number of farm-level spatial data, including location, paddock properties, owner specifications and budgets, it is possible to provide the farm manager with some suggestions regarding the optimal choice of crops and the area to be allocated for each one. To this end, genetic algorithm is used in order to cope with model nonlinearity and a large number of decision variables. In order to test the proposed model, the Mobarakabad district is modeled with 126 agriculture fields, and the optimization model is run for this area. Results showed that the optimization procedure can find more realistic farm-level optimal solutions due to its advantage in adequate modeling of field characteristics, common groundwater resources, and the associated constraints. The results of lumped optimizations could also be used as benchmarks for the purposes of comparison and interpretation.
\end{abstract}

\section{Keywords}

Lumped and Distributed Optimization; Cropping Pattern; Water Resources

\footnotetext{
${ }^{*}$ Corresponding author.

How to cite this paper: Ghasemi, M.M., Karamouz, M. and Teang Shui, L. (2014) Distributed versus Lumped Optimization of Cropping Pattern and Water Resources Utilization. Agricultural Sciences, 5, 257-269. 


\section{Introduction}

Cropping pattern is one of the most important designs and performance parameters in irrigation management which is in direct relationship with water-use efficiency and optimal allocation of soil and water resources [1]. With regards to cropping pattern management, two questions need to be answered: " 1 - which type of crops should be planted?" "2-how much area should be allocated to each crop?" Optimum use of the resources and minimal environmental side-effects should also be considered in answering these questions.

Optimizations of land and water usages for agriculture appear to be vital and unavoidable tasks due to water and land limitations globally. A number of approaches including benefit-cost, functional, programming, and simulation aim at improving the irrigation process by timely allocation of water to crops which are used in order to determine the best cropping pattern and the land area which should be allocated for cultivation of each crop [2]-[5].

However, maximization of the differences between benefits and costs is used by others in order to maximize farm income [6] or net social benefits [7]. Similarly, the costs and benefits approach is widely used for cropping pattern optimization, where the available area of land should be divided between different crops with the aim of achieving maximum net benefits [8].

Furthermore, farm-level optimization models for allocation of land and water to crops are often modified to cover various applications like deficit irrigation, strategic cultivation and sustainable agriculture. Larger scale models, however, are diversely extended to incorporate the concepts of aquifer management, reservoir system operations, intra-basin water transfer, and river quality management [5].

After the Iranian land reform - as a result of which nearly $90 \%$ of the Iranian share-croppers became landowners - several attempts have been made in order to overcome the negative consequences of land fragmentation. The proposed strategies, however, could not tackle such a situation to integrate the farmer community. The inheritance law also augments the land fragmentation problem [9].

The decision-making regarding the choice of the crop requires knowledge about investments, expected benefits, crop water requirements, agriculture policy, material inputs, soil, availability of water, weather conditions, and so on. A simulation-optimization model could establish relationship between those parameters and provide answers to questions like: "what is the best cropping strategy for a given land with certain conditions in terms of water availability?" and "what would be the requirements of such cultivation?"

Irrigation water has a key role in agriculture economic development. The governments have a dominant role in water resources management, but consumption is non-efficient and few budgets are paid for maintenance and operation. Based on Iran constitutional law, the government has the duty for management of surface and groundwater resources [10].

Although in many countries where the irrigated land is used for agriculture, farmers consider themselves rightful for consuming free water or with a little cost [11], the majority of countries are expected to have freshwater shortage problems till 2025 [12]. Therefore, the main constrain for development is water with enough quantity and proper quality.

In irrigation planning and particularly deficit irrigation planning, to establish a relationship between deduction of irrigation water and the resulting decrease in yield is of prime importance. In this vein, many approaches are presented in the literature to define the expected yield of the crops as a function of applied water [13] [14].

A portion of irrigation water provided by groundwater and the rest is supplied from surface waters and precipitation. With modeling of groundwater, it is possible to determine the effect of withdrawal on the water table and storage, which helps farmers and experts in making better decisions about how to use valuable groundwater resource systems [15]. Use of such modeling tools may improve water resources planning to avoid the "tragedy of the commons" that may arise when individuals interact with open-ended resources with incomplete knowledge of the system [16].

MODFLOW is one of the worldwide recognized groundwater models [17]. For utilizing groundwater modeling in optimization procedure, the use of Unit Response Matrix (URM) is recommended by many researchers in order to reduce the computational costs of groundwater models [18] [19].

The inherently spatial nature of most majorities of data in field of agriculture and water resources is persuading to use of such spatial tools for monitoring, analyzing and demonstrating the results. Shamsi [20] defines that Geographic Information System (GIS) is such a tool that helps us to communicate geographic or spatial information. 
In addition to choosing crops based on simulation-optimization procedure, selecting crop types based on comparative advantage in initial steps, can guarantee consideration of social and privet cost aspects.

The Policy Analysis Matrix (PAM) is constructed by structuring the tradable and domestic input costs, revenues, and profits, each as shadow and market values. By doing this, PAMs are calculated for each crop in each year with respect to the associated selling prices and exchange rate values [21] [22]. PAM enables farmers and decision makers to refine the choice of crops by addressing local and national policy with social and privet cost.

Up to now, the majority of the cropping pattern and water resources optimization models can be put into two main strands: lumped plain models (whole area suggestions) and farm models [23]-[25]. Although these studies dealt with the variations of various parameters by means of random sampling methods, data had not any spatial features and were considered constant throughout the whole study area.

In the present study, a detailed spatially-oriented model is presented for optimization of cropping patterns and conjunctive-use decisions, which could model farm area, availability of water from different resources, and specific conditions of each of the farms exclusively. The proposed model takes advantage of URM-based groundwater simulation, PAM-based economic analysis and GIS connectivity in order to form an integrated framework for more realistic decision-making on cropping patterns and water allocation rules. Afterwards, a thorough comparison has been made between the outputs of these two approaches, namely lumped and distributed modeling, under various climatic, environmental, and economic conditions. To do so, the two optimization models are solved using a modified Genetic Algorithm.

\section{Material and Methods}

\subsection{Case Study}

The study area is Mobarakabad district, settled on the Qaderabad-Madarsoleiman plain in Pasargad County (Figure 1). Due to having a semi-arid climate, the majority of the irrigational water is withdrawn from the groundwater resources. Uncontrolled growth of the agricultural activities in the area has resulted water tables drop rates as high as 1.2 meters per annum [26].
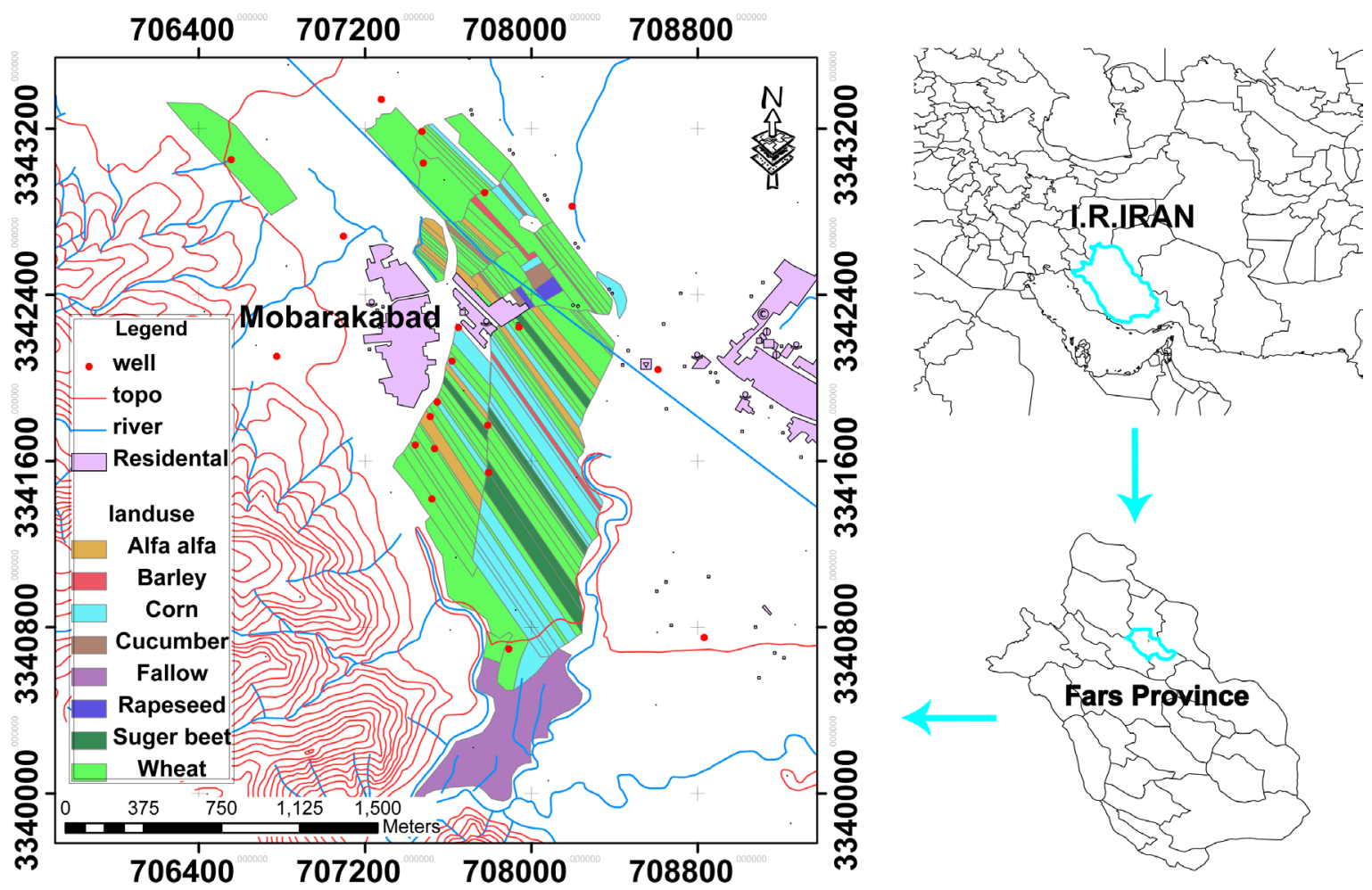

Figure 1. Location of the Mobarakabad village. 
Figure 1 illustrates the location and the actual cropping pattern of the study area in 2007, which may clearly show that a large area is allocated for cultivation of wheat. The agricultural lands of the Mobarakabad village are divided into 126 fields with 63 owners. The total cultivated area is 207.8 hectares, with an average of 1.647 hectare per field [27].

One aqueduct and 17 groundwater extraction wells supply the agriculture water requirements of this area. Mobarakabad aqueduct's fountain is located outside of the case study area and groundwater extraction is determined to not having any effects on its flow. The discharge of this aqueduct depends on climatic conditions and ranges from 20 lit/sec during droughts and up to $150 \mathrm{lit} / \mathrm{sec}$ in wet conditions. The share of each field in 10-day time-steps is currently being determined based on each field's area. Currently, the prevalent cultivated crops across the area are consisted of various winter, summer, and annual crops.

\subsection{Optimization Procedure}

A proper and realistic model for optimization of the cropping patterns and water utilization is a model that can optimally allocate water between various crops, throughout time, and spatially (between the fields).

Optimization methods are different depending on the objective function and constrain formula and equations. Although the programmer can choose particular type of optimization, type of equation may force to select a special type of model. For instance, if one of the objective functions or constraints is developed as nonlinear, the structure of the optimization would be nonlinear and the modeler has to use appropriate method for solving it, using some methods like evolutionary algorithms. Depending on the local, regional, and national policies, details and coefficient of the objective function and constrains equations will be set in such a model (Figure 2).

\subsubsection{Objective Function and Constraint}

Due to the shortage of water resources, the objective function of the optimization model is maximizing the benefit with respect to irrigation water use. The objective function of the proposed model is as follows, which is subjected to several constraints:

1) Model

$$
\begin{aligned}
& \operatorname{MaxZ}=\sum_{f=1}^{F} \sum_{c=1}^{C}\left(Y_{f c} \times \operatorname{Pr}_{c} \times \alpha_{f c} \times A_{f}\right) \\
& -\sum_{f=1}^{F} \sum_{c=1}^{C}\left(C_{f} \times \alpha_{f c} \times A_{f}+\sum_{T}^{t=1} g_{f c t} \times P_{g}+s_{f c t} \times P_{s}\right)
\end{aligned}
$$

\section{2) Constraints}

Each function has several constrains that define the tolerance of the items affecting the objective function and can help to achieve a better optimization solution. The considered constraints in this case are:

$$
\begin{gathered}
0 \leq \alpha_{f c} \leq x_{f c} \\
\sum_{f=1}^{F} A_{f} \leq A_{t} \\
0 \leq s_{f c t} \leq\left(S_{\max }\right)_{f c} x_{f c} \quad \forall f, c, t \\
0 \leq g_{f c t} \leq\left(G_{\max }\right)_{f t} x_{f c} \quad \forall f, c, t
\end{gathered}
$$

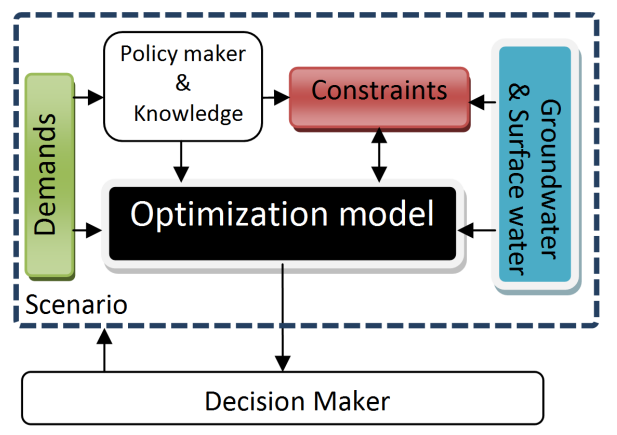

Figure 2. Optimization procedure flowcharts. 


$$
\begin{gathered}
w_{f c t}=s_{f c t}+g_{f c t} \forall f, c, t \\
\left(Y_{a}\right)_{f c}=x_{f c} \times\left(Y_{p}\right)_{c}\left(\prod_{t=1}^{T}\left[1-K_{y t}\left(1-\frac{\left(W_{a}\right)_{f c t}}{\left(W_{p}\right)_{f c t}}\right)\right]\right) \\
\left\{\begin{array}{l}
\forall f=1, \cdots, F \\
\forall c=1, \cdots, C
\end{array}\right. \\
\left(W_{p}\right)_{f c t}=\frac{I_{f c t} \times A_{f} \times 10}{\left(E_{a}\right)_{f}} \\
I_{f c t}=\left(E T_{a}\right)_{c t}-\left(P_{e}\right)_{t} \\
\left(W_{a}\right)_{f c t}=\left(1-X_{c}\right)\left(W_{p}\right)_{f c t} \\
\sum_{f=1}^{F} \sum_{c=1}^{C} g_{f c t} \leq\left(G_{\max }\right)_{t} \quad \forall t=1, \cdots, T \\
\sum_{f=1}^{F} \sum_{c=1}^{C}\left(w_{a}\right)_{f c t} \leq Q_{t} \quad \forall t=1, \cdots, T \\
\Delta h=P(g) \\
\sum_{k=0}^{n} \Delta h_{t} \leq(\Delta h)_{\text {allowable }}
\end{gathered}
$$

where:

$Z$, net benefit of the crop cultivation during the planning horizon; $F$, number of fields; $C$, number of crops; $T$, number of periods; $s_{f c t}$, The allocated surface water for field $f$ in period $t$ to crop $c ; g_{f c t}$, the allocated groundwater for field $f$ in period $t$ to crop $c$; $P_{s}$, surface water price; $P_{g}$, groundwater price; $\left(Y_{a}\right)_{f c}$, actual crop production for specified crop $c$ in field $f ;\left(Y_{p}\right)$, potential yields of crop $c$; $K_{y t}$, yield response factor in growth stage $t ; A_{f}$, agricultural area in field $f ; \alpha_{f c}$, percentage of allocated area to specified crop $c$ in field $f$; $C_{f}$, crop production cost in field $f ; P r_{c}$, market price of crop $c ; I_{f c t}$, irrigation water requirement for crop $c$ in period $t ;\left(E T_{a}\right)_{c t}$, actual evapotranspiration for crop $c$ in period $t ;\left(P_{e}\right)_{t}$, effective precipitation in period $t$; $\left(E_{a}\right)_{f}$, irrigation application efficiency; $\left(S_{\min }\right)_{f t}$, minimum available surface water for field $f$ in period $t$; $\left(S_{\max }\right)_{f t}$, maximum available surface water for field $f$ in period $t ;\left(G_{\max }\right)_{f t}$, maximum available groundwater for field $f$ in period $t ; Q_{t}$, maximum available water in period $t$ and calculated from:

$$
Q_{t}=\sum_{f=1}^{F}\left(\left(S_{\max }\right)_{f t}+\left(G_{\max }\right)_{f t}\right)
$$

where $\left(G_{\max }\right)_{t}$ is the maximum available groundwater for all fields in period $t$ and $X_{c}$ is maximum allowable reduction of irrigation water.

3) Variables

$$
x_{f c}=\left\{\begin{array}{cc}
1 & \text { crop } c \text { is planted in field } f \\
0 & \text { otherwise }
\end{array}\right.
$$

$x_{f c}$ is the decision variable of the optimization model, defining whether crop $c$ is cultivated in farm $f$ or not.

Furthermore, the widely popular MODFLOW model is used as the core of groundwater simulation model. For calculating water table drawdown with respect to well discharge, however, an embedded URM function is employed. The URM function for total of $j$ wells based on additivity principle is:

$$
s(k, n)=\sum_{i=1}^{n} \sum_{j=1}^{j} \beta_{k}(k, j, n-t+1) q(j, t)
$$

where $s(k, n)$ is change of water table level at well $k$ at the end of the time period of $n$, and $\beta_{k}(k, j, n-t+1)$ is the unit response coefficient, which is defined as the unit change of the water table at well $k$ during $n$, due to 
the excitation (withdrawal/recharge) at well $j$ during $t$.

$\beta$ is a function of the distance between wells, the well diameters, the hydraulic conductivity of the aquifer, the recharge of the aquifer, boundary conditions, and the starting heads [28]. The above-mentioned equations could also be used for multi-aquifer systems [29].

As regard the irrigation requirement, FAO Penman-Monteith approach also known as PM-FAO56 is applied for estimating actual evapotranspiration [30] [31].

For calculation of water requirement of various crops across the study area, the data from Takht-e-Jamshid meteorological station and Madarsoleiman pluviometric station were used. Other data used in this set of equations include crop coefficients and growth stage durations acquired from previous studies on the study area [27].

PAM method is employed for refining the number of crops to a smaller set of feasible choices. For this purpose, costs and benefits expected from each crop is acquired from annual agricultural census and was used to build PAM. Next, the Domestic Resources Cost (DRC) and Efficient Protection Coefficient (EPC) indices are considered as two criteria for filtering of unsuitable crops from the model prior to objective function optimization [32].

Several meta-heuristic optimization models could be used to solve these non-linear equations. Actually there is no consensus among researchers about the best meta-heuristic model. Genetic algorithms (GAs) have been widely used in groundwater quantity and quality management and conjunctive-use of surface and groundwater resources. Therefore, in this study, the non-linear problem is solved using a GA-based optimization model, due to the promising efficiency of GA in handling large numbers of decision variables.

In this method, the input options for the modeled system are mathematically defined as genes by these methods [33]. With the "fittest" solutions cross-breeding and mutating over generations, the optimal combination of traits is finally reached. Genetic algorithms have a good chance of identifying the global optimum of the search space.

In genetic algorithm approach, after real encoding of the decision variables and placing them in a chromosome, the initial population will be generated and fitness for every chromosome will be estimated. This process will continue until a satisfactory result is reached. For each step of GA procedure, several types of operators could be used. Choosing one of them depends on the chromosome structure, the nature of objective function and constrain equations. Therefore, it is possible to choose items and methods by trial and error and by having an eye on the existing literature. These strategies could easily be implemented given the diversity of available codes and software.

\subsubsection{Optimization Cases}

Two optimization cases are considered. First structure is the holistic allocation of land and water to crops at plain level:

\begin{tabular}{lllllllllllll}
\hline$\alpha_{1}$ & $\alpha_{2}$ & $\ldots$ & $\alpha_{\mathrm{c}}$ & $S_{1}$ & $S_{2}$ & $\ldots$ & $S_{36}$ & $G_{1}$ & $G_{2}$ & $\ldots$ & $G_{36}$ \\
\hline
\end{tabular}

$\alpha_{1}$ to $\alpha_{\mathbf{n}}$ are the percentage of allocated land for crop 1 to $c$;

$S_{1}$ to $S_{36}$ are amount of surface irrigation water in decade 1 to 36 ;

$G_{1}$ to $G_{36}$ are amount of groundwater irrigation water in decade 1 to 36 .

Second structure is the allocation of the water resources and crops to each field separately:

\begin{tabular}{ccccccc}
\hline$C_{c 1}$ & $\alpha_{c 1}$ & $X_{1 c 1}$ & $X_{2 c 1}$ & $X_{3 c 1}$ & $X_{4 c 1}$ & $X_{5 c 1}$ \\
$C_{c 2}$ & $\alpha_{c 2}$ & $X_{1 c 2}$ & $X_{2 c 2}$ & $X_{3 c 2}$ & $X_{4 c 2}$ & $X_{5 c 2}$ \\
$\ldots$ & $\ldots$ & $\ldots$ & $\ldots$ & $\ldots$ & $\ldots$ & $\ldots$ \\
$C_{c f}$ & $\alpha_{c f}$ & $X_{1 c f}$ & $X_{2 c f}$ & $X_{3 c f}$ & $X_{4 c f}$ & $X_{5 c f}$ \\
\hline
\end{tabular}

$\mathrm{C}_{c f}$ specified crop $c$ allocated to the field number $f$;

$X_{1 c f}$ to $X_{5 c f}$ are the amount of irrigation water deduction (surface water and groundwater) in duration 1 to 5 and in field 1 to $f$ for crop $c$; 
$\alpha_{1 j}$ to $\alpha_{n j}$ are the percentage of allocated land of farm 1 to $n$ for crop $j$.

\subsubsection{Scenarios}

The optimal solution cannot be simply proposed and employed without considering other aspects such as: deficit irrigation, partial planting, land integration, water prices, climatic conditions, allowable water table drawdown and so on. Hence, the optimization code must be flexible to change some of the above-mentioned parameters. The optimization package, in such case, provides answer to different questions by offering several optimal alternatives to decision makers.

The optimization code is developed and run in Mat lab software. Lastly, the optimization procedure ends in a GIS environment, where the final results are presented in GIS-compatible formats and map reports are generated.

\section{Results and Discussion}

\subsection{Water Price}

The private costs of utilization of each unit of water could be considered as the sum of fixed and variable costs. For calculation of annual fixed costs, the future costs were used:

$$
A=F\left[\frac{i}{(1+i)^{n}-1}\right]
$$

where $A$ is equivalent annual cost, $F$ is future worth, $I$ is interest rate, and $N$ is the number of interest periods. The above equation splits the interest rate into the cost per year of owning and operating the asset over its entire lifespan.

Based on the regional data, the wells have average depth of 18.5 meters and pipes with 4 inch diameter are usually used. The detailed annual costs of owning and operating wells across the study area is presented in Table 1.

All of the equivalent annual costs are presented in Table 1 as fixed costs of operating wells in the study area.

With respect to average working time of the pumps during planting, growth, and harvest phases, the costs associated with fuel, oil, maintenance, and repair are considered as variable costs for diesel pumps, while costs of electricity, maintenance, and repair could be considered for wells with electrical pumps. Moreover, fixed and variable costs per volume of water are evaluated by dividing the equivalent annual costs and variable costs by the volume of pumped water. The sum of fixed and variable costs per unit of water is 109.7 Rials for $12,095 \mathrm{~m}^{3}$ and 385 hours of pumping (74.7 Rials for fixed and 35 Rials for variable costs). These values perfectly match with those that evaluated using Depth-Costs relationship provided earlier by Abdolahi-ezatabadi and Soltani [34].

In order to analyze the expected profitability of cultivation of various crops, the ratio indicators are calculated for all of the crops. The results of these calculations for the year 2007 showed that the sunflower, dry barley, bean and potato have low comparative advantage due to having high values of DRC. Furthermore, from the crops with DRC values smaller than one, those crops which have EPC values greater than one (winter wheat,

Table 1. Annual costsof owning and operating wells in Fars provice (in IR Rials).

\begin{tabular}{|c|c|c|c|c|}
\hline Description & Cost & Salvage Value & Effective Life & Uniform Annual Cost \\
\hline Well Drilling & 7360 & - & 10 & 328.673 \\
\hline Turbine (pump) & 2700 & 800 & 15 & 33.862 \\
\hline Engine & 34,000 & 12,000 & 15 & 392.086 \\
\hline Pipe & 6072 & 3300 & 15 & 49.403 \\
\hline \multirow[t]{2}{*}{ Connections, Chassis and Discharge Valve } & 7100 & 1500,000 & 15 & 99.804 \\
\hline & & & TOTAL & 903.827 \\
\hline
\end{tabular}


barley, corns, rapeseed and cucumber) can be considered as the products that enjoy efficient protections provided by government policies. Based on the definition of EPC, the values higher than one are usually due to presence of incentives for production of a crop, and values smaller than one illustrate presence of effective tariffs on production of the crop. Hence, it can be concluded that the government policies and market disruptions tend toward protection of winter wheat, irrigated barley, corns, rapeseed and cucumber in Pasargad County.

The presented mathematical details showed sample applications of surface water and groundwater management by a farm-scale hydrologic economic model that integrates agronomic, climatic, irrigation, hydro geological and economic aspects of irrigated agriculture. Optimum mix of land use to keep the water table within acceptable limits while maximizing the benefit is the main objective of model. Alternatively, the model can simulate water balance and economics of a given cropping preference. Ultimately, proper selection of crops can help reduce water table drawdown problems and ensure the economic viability of farms.

The constraints subjected to this study are change in water table level, maximum and minimum areas of land and water allocation to the farm constraints.

In real world, the decision-maker does not have all necessary power to impose its agricultural plan on the farmer community. For instance, private ownership of water and land resources and the resulting legal burdens, as well as persuasion of personal goals by farmers may lead to degradation of groundwater resources and reduction of economic benefits at plain level.

Nevertheless, lumped optimization of cropping patterns and optimal allocation of surface and groundwater resources, however idealistic, could perfectly reveal the hydrological potential of the area to produce food, improve labor, and generate income. In other worlds, although social and legal aspects of the agricultural activities are overlooked in lumped optimization models, this approach could be used as means of improving the awareness of the decision-maker regarding the potential of the land, and could form the basis of further reformative strategies. When lumped optimizations are considered by a planner, it indicates that the planner assumes land consolidation which is in contrary to land fragmentation. Given this wrong assumption, such results are not applicable in real world.

Due to the fact that there are 17 agricultural wells across the area and we have defined 36 time-steps of 10-day long over a year, the URM associated with pumping from each well is a matrix with $17 \times 36$ arrays. Thus, the main URM of the study area aggregating the unit response matrices of each well is a $17 \times 17 \times 36$ matrix. This URM is incorporated in a MATLAB function, which could evaluate the drawdown of water table at each well, based on given time-series of the pumping rates at the wells.

Figure 3 shows how this code is incorporated in the optimization model, for controlling the water table draw downs resulting from proposed irrigation plans.

\subsection{Lumped Optimization}

The results acquired from running the lumped optimization model for various scenarios are presented in Figure 4. As it could be seen on the figure, the total net benefits increase with allowing for more and more groundwater exploitation. That is, in water preservation scenarios, the least net benefit is associated with 1 meter drawdown of groundwater table.

Also, increasing the price of the groundwater has resulted in the decrease of the total cultivated area and total net benefits. Moreover, the cropping pattern of the area most notably responds to this increase by reducing the area allocated for cultivation of canola.

The results of the meteorological scenarios demonstrate other interesting effects on the area.

The total cultivated area has changed from 0.3 of the total lands during drought conditions, to 0.92 and 1 during normal and wet conditions, respectively. As a result, the total net benefits during wet conditions increase by a factor of 2.4 and 5.4 in comparison to normal, and drought conditions, respectively. The most noticeable change of the cropping pattern with respect to increase of the precipitations is the increase of the planted area of watermelon up to the surprisingly high share of 85 percent in wet years. Our experiments on excluding the watermelon from the pattern would result in a 37 percent decrease of the total net benefits.

The evolutionary optimization procedure should be done in a supervised manner. That is, the global optimum of each case is only reliable when the obtained result is verified through multipleruns of the algorithm.

\subsection{Distributed Optimization}

Contrary to lumped approach that assumes whole area as a single farm, distributed optimization takes into account 


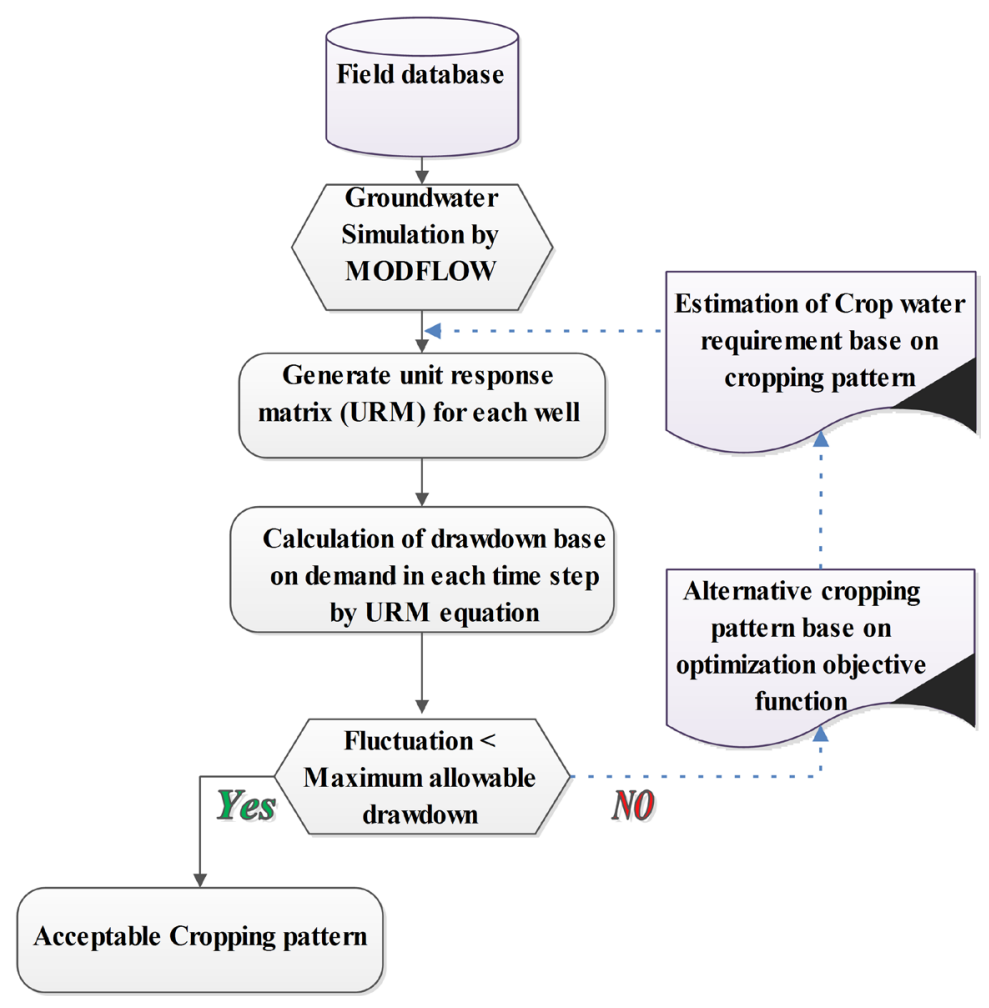

Figure 3. The use of URM for groundwater modeling in cropping pattern optimization scheme.

\section{Optimal net revenues from lump and distributed models}

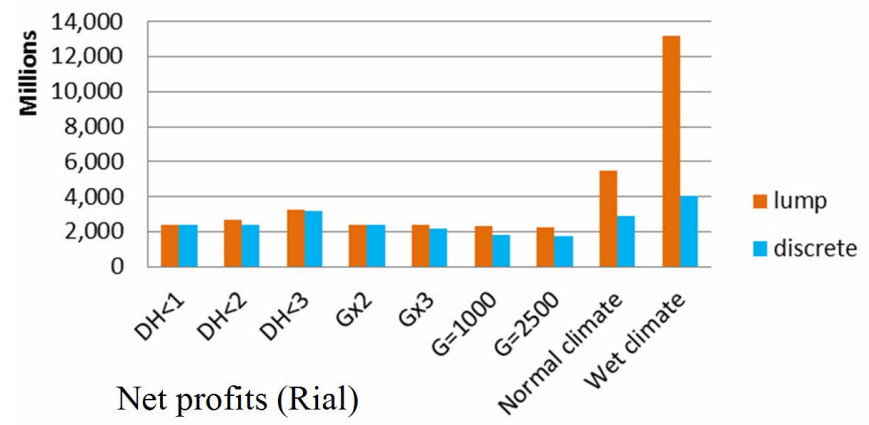

Figure 4. The results of lumped and distributed optimization models.

real world conditions, e.g., land fragmentation. Due to the complexity of mixed integer non-linear optimization in this case, some special considerations should be given in order to improve the efficiency of the algorithm.

In Figure 5, the wavy pattern seen on the mean fitness of the population during the optimization procedure is related to the use of a flexible crossover fraction modulator. In the proposed genetic algorithm, stall of the best fitness for a certain number of iterations triggers a mechanism that reduces the crossover to 0.3 , elite count to 1 individual, and consequently, the mutation becomes the major player in the search algorithm. This mechanism for domination of random search approach helps to break pre-mature convergence and provides the population with new individuals. If the algorithm successfully finds a new fit individual these parameters count roll back to user-set values.

Regarding running the distributed model, the net benefit of the best chromosome in distributed optimization is calculated to be 2369452229.565384 IR. Rials, with respect to 1 meter allowable water table drawdown. In such 
case, although the amount of total benefit is less than lumped optimization, it is almost close to it. The difference between the results of lumped and distributed optimization with same assumption shows the costs of land fragmentation. Figures 6 and 7 show the optimum cropping pattern and the cropping percentage of each field across the study area, respectively. Figure 4, however, illustrates the net revenue results evaluated from each scenario.

Result of the case study shows that the proposed algorithms and models are capable of optimization of cropping pattern and water resources utilization both in lumped and distributed conditions. Different applicable scenarios took into practice and the results are calculated. Clearly, the lumped model tends to overestimate the expected net revenues, due to its failure in proper modeling of various parameters, most notably the availability of groundwater and surface water.

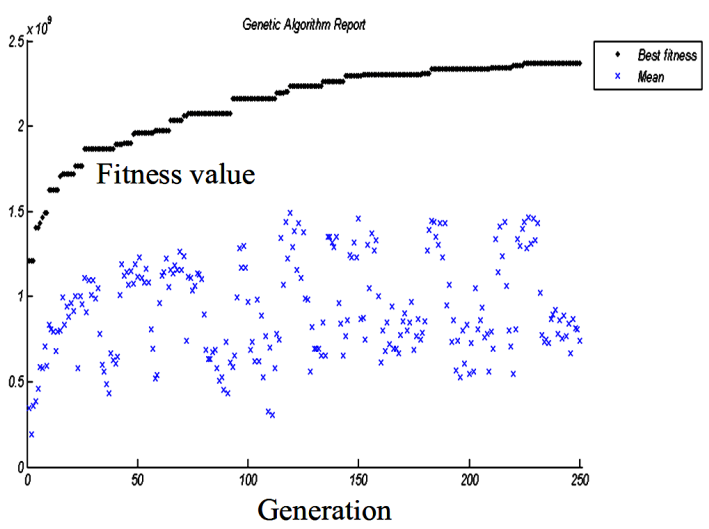

Figure 5. Best and average fitness of the population.

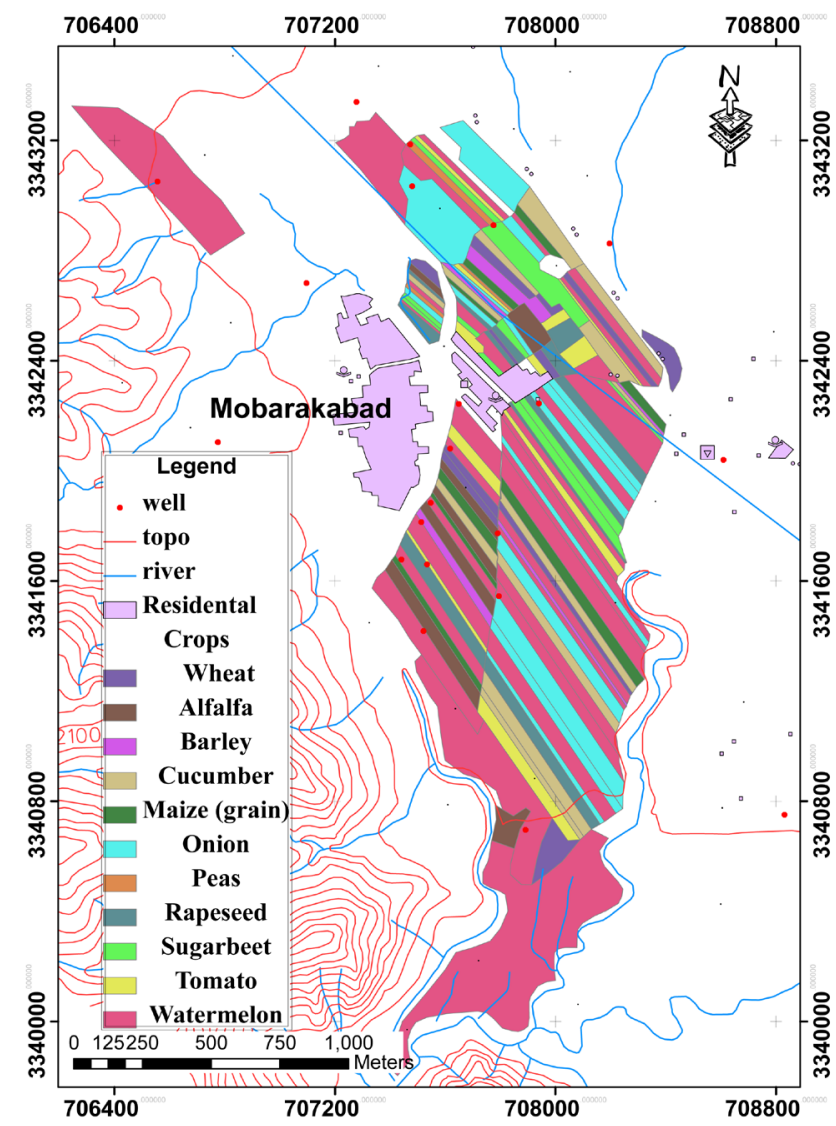

Figure 6. Optimal cropping pattern of the study area. 


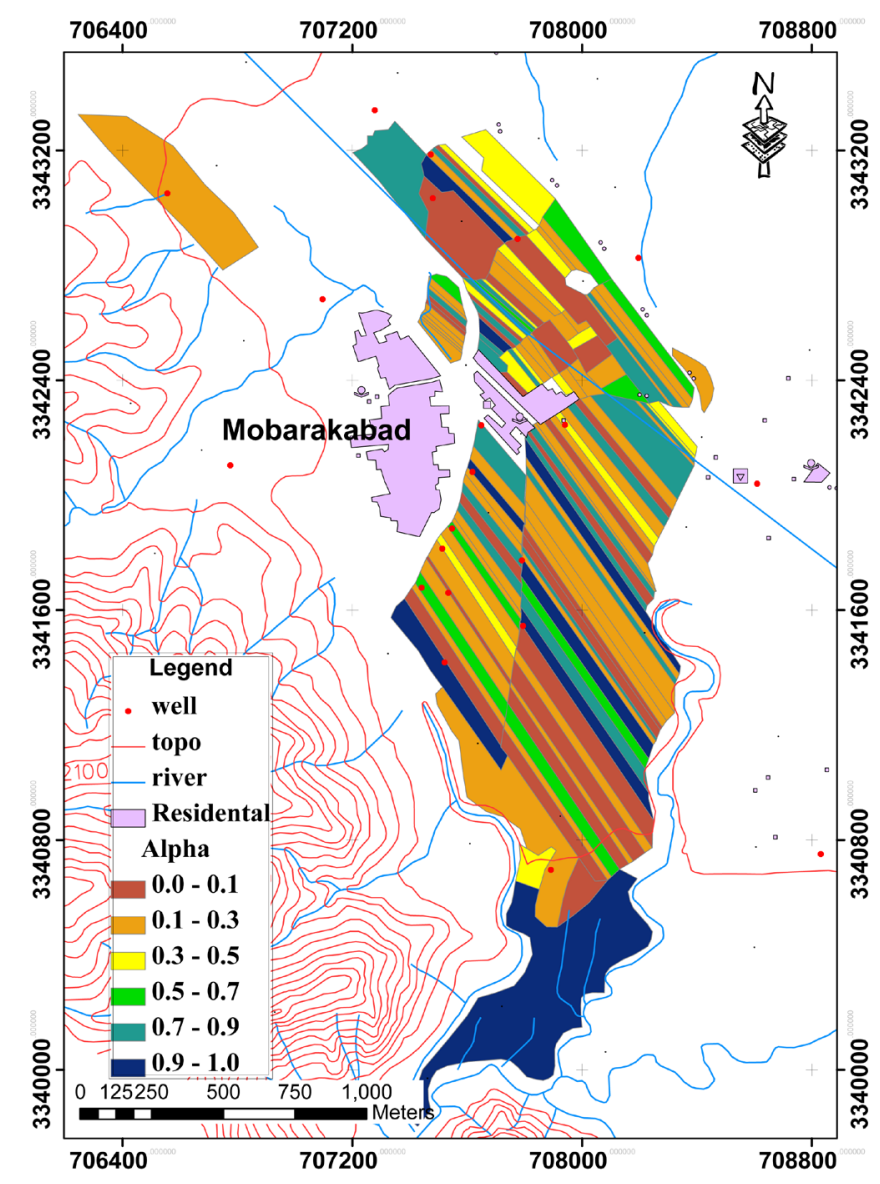

Figure 7. Optimal cropping percentage of each field.

Besides the optimal cropping pattern, partial planting fraction, surface and groundwater irrigation plan of each field, and various other types of outputs the model provides, the map-based results improve the ability of expert as decision maker for participating in agriculture planning. In addition, flexibility of such model helps to have interactive discussion and make decision by premise.

\section{Conclusions}

The results of the present study showed that the suggested procedure can be effectively employed for proposing distributed cropping pattern decisions with respect to conjunctive utilization of surface and groundwater resources.

Our study showed that although lumped and distributed optimization methods are different in scope and procedure, failing to account for distributed optimization conditions may result in overestimation of the net income and/or underestimation of input usage. In other words, the planner would connive in the differences in local and regional programming.

While the results could be clearly demonstrated under certain conditions, the difference between these two modeling approaches would be significant and must be taken into consideration. Given the implications of the newly proposed method, it is recommended that decision makers optimize the water resources and cropping pattern in both lumped and distributed conditions, so that they could persuade farmers for consolidation of agricultural lands. At worst, it would be a signal for these farmers that they must expect less income and more waste of resources.

\section{References}

[1] Montazar, A. and Rahimikob, A. (2008) Optimal Water Productivity of Irrigation Networks in Arid and Semi-Arid 
Regions. Irrigation and Drainage, 57, 411-423. http://dx.doi.org/10.1002/ird.376

[2] Noory, H., Liaghat, A.M., Parsinejad, M. and Haddad, O.B. (2012) Optimizing Irrigation Water Allocation and Multicrop Planning Using Discrete PSO Algorithm. Journal of Irrigation and Drainage Engineering, 138, 437-444. http://dx.doi.org/10.1061/(ASCE)IR.1943-4774.0000426

[3] Parsinejad, M., Yazdi, A.B., Araghinejad, S., Nejadhashemi, A.P. and Tabrizi, M.S. (2013) Optimal Water Allocation in Irrigation Networks Based on Real Time Climatic Data. Agricultural Water Management, 117, 1-8. http://dx.doi.org/10.1016/j.agwat.2012.10.025

[4] Sadegh, M. and Kerachian, R. (2011) Water Resources Allocation Using Solution Concepts of Fuzzy Cooperative Games: Fuzzy Least Core and Fuzzy Weak Least Core. Water Resources Management, 25, 2543-2573. http://dx.doi.org/10.1007/s11269-011-9826-x

[5] Singh, A. (2012) An Overview of the Optimization Modelling Applications. Journal of Hydrology, 466-467, 167-182. http://dx.doi.org/10.1016/j.jhydrol.2012.08.004

[6] Ghahraman, B. and Sepaskhah, A.-R. (2002) Optimal Allocation of Water from a Single Purpose Reservoir to an Irrigation Project with Pre-Determined Multiple Cropping Patterns. Irrigation Science, 21, 127-137. http://dx.doi.org/10.1007/s002710100040

[7] Soltani, G.R., Bakhshoodeh, M. and Zibaei, M. (2009) Optimization of Agricultural Water Use and Trade Patterns: The Case of Iran. In: Economic Research Forum Working Papers, No. 508.

[8] Karamouz, M., Zahraie, B., Kerachian, R. and Eslami, A. (2008) Crop Pattern and Conjunctive Use Management: A Case Study. Irrigation and Drainage, 59, 161-173.

[9] Craig, D. (1978) The Impact of Land Reform on an Iranian Village. Middle East Journal, 32, 141-154.

[10] Bakhshi, A. (2005) Water Resources Economic. Agricultural Planning \& Economic Research Institute (A.P.E.R.I.), 76.

[11] Mahmoud, A.-Z. (2002) Water Pricing in Irrigation Agriculture. In: Irrigation Water Policies: Micro and Macro Considerations, Agadir.

[12] Seckler, D., Amarasinghe, U.A., Molden, D., de Silva, R. and Barker, R. (1998) World Water Demand and Supply, 1990 to 2025: Scenarios and Issues. International Water Management Institute, Colombo, 52.

[13] Rao, N., Sarma, P. and Chander, S. (1988a) A Simple Dated Water-Production Function for Use in Irrigated Agriculture. Agricultural Water Management, 13, 25-32. http://dx.doi.org/10.1016/0378-3774(88)90130-8

[14] Ghahraman, B. and Sepaskhah, A.R. (2004) Linear and Non-Linear Optimization Models for Allocation of a Limited Water Supply. Irrigation and Drainage, 53, 39-54. http://dx.doi.org/10.1002/ird.108

[15] Salcedo-Sánchez, E.R., Esteller, M.V., Garrido Hoyos, S.E. and Martínez-Morales, M. (2013) Groundwater Optimization Model for Sustainable Management of the Valley of Puebla Aquifer, Mexico. Environmental Earth Sciences, 70, 337-351. http://dx.doi.org/10.1007/s12665-012-2131-z

[16] Reeves, H.W. and Zellner, M.L. (2010) Linking Modflow with an Agent-Based Land-Use Model to Support Decision Making. Ground Water, 48, 649-660. http://dx.doi.org/10.1111/j.1745-6584.2010.00677.x

[17] Harbaugh, A.W. (2005) MODFLOW-2005, the US Geological Survey Modular Ground-Water Model-The GroundWater Flow Process. US Geological Survey Techniques and Methods, Volume 6-A16.

[18] Larroque, F., Treichel, W. and Dupuy, A. (2008) Use of Unit Response Functions for Management of Regional Multilayered Aquifers: Application to the North Aquitaine Tertiary System (France). Hydrogeology Journal, 16, 215-233. http://dx.doi.org/10.1007/s10040-007-0245-2

[19] Alimohammadi, S., Afshar, A. and Ghaheri, A. (2005) Unit Response Matrix Coefficients Development: ANN Approach. Proceedings of the $5^{\text {th }}$ WSEAS/IASME International Conference on Systems Theory and Scientific Computation, Malta, 15-17 September 2005, 17-25.

[20] Shamsi, U.M. (2005) GIS Applications for Water, Wastewater, and Stormwater Systems. CRC Press, Boca Raton. http://dx.doi.org/10.1201/9781420039252

[21] Monke, E. and Pearson, S.R. (1989) The Policy Analysis Matrix for Agricultural Development. Cornell University Press, Ithaca.

[22] Yao, S. (1997) Comparative Advantage and Crop Diversification; A Policy Analysis Matrix for Thai Agriculture. Journal of Agricultural Economics, 48, 211-222. http://dx.doi.org/10.1111/j.1477-9552.1997.tb01146.x

[23] Sepaskhah, A.R., Azizian, A. and Tavakoli, A.R. (2006) Optimal Applied Water and Nitrogen for Winter Wheat under Variable Seasonal Rainfall and Planning Scenarios for Consequent Crops in a Semi-Arid Region. Agricultural Water Management, 84, 113-122. http://dx.doi.org/10.1016/j.agwat.2006.01.008

[24] Sabbaghpour, S., Naghashzadehgan, M., Javaherdeh, K. and Haddad, O.B. (2012) HBMO Algorithm for Calibrating Water Distribution Network of Langarud City. Water Science and Technology, 65, 1564-1569. 
http://dx.doi.org/10.2166/wst.2012.045

[25] Klocke, N.L., Stone, L.R., Clark, G.A., Dumler, T.J. and Briggeman, S. (2006) Water Allocation Model for Limited Irrigation. Applied Engineering in Agriculture, 22, 381-389. http://dx.doi.org/10.13031/2013.20458

[26] Pouyan-Shiraz-Consultants (2012) A Survey of Water Resources in Qaderabad-Madar Soleiman in Bakhtegan Basin for the Power Ministry. Fars, Boushehr, and Kohgilouye-Bouyr-Ahmad Regional Water Authority.

[27] Ghasemi, M.M., Bardideh, M. and Jahanafrooz, A. (2010) A Simple Method For Preparing Farms Spatial Database (A Case Study on the Destrict of Pasargad in Fars Province). MRSS 6th International Remote Sensing \& GIS Conference and Exhibition, Kuala Lumpur, 28-29 April 2010.

[28] Maddock, T. (1972) Algebraic Technological Function from a Simulation Model. Water Resources Research, 8, 129134. http://dx.doi.org/10.1029/WR008i001p00129

[29] Yazicigil, H. (1990) Optimal Planning and Operation of Multiaquifer System. Journal of Water Resources Planning and Management, 116, 435-454. http://dx.doi.org/10.1061/(ASCE)0733-9496(1990)116:4(435)

[30] Allen, R., Pereira, L.S., Raes, D. and Smith, M. (1998) Crop Evaporation: Guidelines for Computing Crop Requirements. FAO Irrigation and Drainage Paper 56, Food and Agriculture Organization of the United Nations, Rome, 135.

[31] Alizadeh, A. and Kamali, G.A. (2007) Crops Water Requirements. Imam Reza University Press, Mashhad.

[32] Khademipoor, G. and Najafi, B. (2007) Effects of Government Protection Policies on Economic Incentives of Main Crops: A Policy Analysis Matrix Approach (PAM). 6th Agricultural Economic Conference, Mashhad, 30-31 October 2007.

[33] Karamouz, M., Tabari, M.M.R. and Kerachian, R. (2007) Application of Genetic Algorithms and Artificial Neural Networks in Conjunctive Use of Surface and Groundwater Resources. Water International, 32, 163-176. http://dx.doi.org/10.1080/02508060708691973

[34] Abdolahi-ezatabadi, M. and Soltani, G. (1999) Computation of the External Cost of Overpumping from Water Resources, a Case Study of Rafsanjan (in Persian). Iranian Journal of Agricultural Sciences, 30, 36-44. 